\title{
PROGNOSIS OF THE EARLY DISEASE RECURRENCE IN PATIENTS WITH LOCALISED PROSTATE CANCER AFTER RADICAL SURGERY
}

\author{
Omelchenko V.P. ${ }^{1}$, Bova Ph.S. ${ }^{2}$, Demidova A.A. ${ }^{1}$ \\ ${ }^{1}$ The Rostov state medical university, Rostov-on-Don, e-mail: ms.victorial11@mail.ru; \\ ${ }^{2}$ The State Budgetary organization of the Rostov Region "Regional Hospital №2", Rostov-on-Don, e-mail: \\ alald@inbox.ru
}

Aims.

Aim: to improve the effectiveness of prognosis of early recurrence in patients with localised prostate cancer (PC) after radical surgery by assessment of expression of prostate-specific antigen PCA3 [prostate cancer associated $3]$ in the urine sediment and exosomes.

Materials and methods.

The study included 148 patients with localised PC. The serum level of prostate-specific antigen (PSA) was determined for all patients by enzyme immunoassay at the baseline and every 3 months after radical prostatectomy (RPE) for two years. Patients were divided into two subgroups depending on the presence or absence of biochemical recurrence (BR). Expression of PCA3 gene was determined in the urine sediment and exosomes by PCR [polymerase chain reaction] in real time, relative to the reference human kallikrein gene KLK3 [kallikrein related peptidase 3].

Results.

PCA3 gene expression level in urine exosomes of patients with prostate cancer and prostatic intraepithelial neoplasia grade 2 (PIN2) was higher in the subsequent recurrence compared with a favourable course of the disease. With a decrease of $\triangle \mathrm{Ct}$ PCA3-KLK3 to less than 1.86 inclusive in urine sediment, BR in patients with $\mathrm{PC}$ and PIN2 in the peritumoral area occurred more frequently $(83 \%$ vs. $45 \%, \mathrm{p}=0.008)$.

Conclusions.

Prognostic significance of the evaluation of PCA3 gene expression in the postmassage urine sediment and exosomes for determining BR risk after RPE in patients with localised PC is higher than the determination of PSA in the blood serum. With an increase in the PCA3 gene expression in the postmassage urine sediment and exosomes in patients with localised PC, the BR risk within two years after RPE increases.

Keywords: prostate cancer, biochemical recurrence, prostate-specific antigen 3, urine exosomes.

\section{INTRODUCTION.}

In recent years, clinicians have widely adopted systems for diagnosing, staging, and monitoring prostate cancer (PC). This has lowered the age of patients diagnosed with primary PC and increased the proportion of those with localized PC [1]. The Russian National Cancer Care Report states that in 2016, 56\% of PC patients had Stage I or II, cf. 37.6\% in 2006 [1]. Blood serum is tested for prostate-specific antigen (PSA) for diagnosis and monitoring [2]. This is an undoubtedly efficient screening and monitoring method. However, various researchers have shown that only $25 \%$ of men who have the gray-zone concentration of serum PSA (4 to $10 \mathrm{ng} / \mathrm{ml}$ ) have PC; $70 \%$ to $80 \%$ biopsies turn out to be unnecessary [3]. It should be noted that PSA is an organ-specific substance rather than a cancer-specific marker. PSA levels may increase above the reference values when the prostate is exposed to interventions: massage, surgery, biopsy, acute urinary retention, or ultrasound; or when there are benign or inflammatory processes [4].

Estimating the expression of prostate cancer antigen 3 (PCA3) in the prostate tissue shows promise as a diagnostic technique. $P C A 3$ hyperexpression is strictly specific to $\mathrm{PC}$ and its metastases; it is not typical of benign processes [5]. Exosomes are present in mRNA and are involved in cell communications, which is why they have been involved in genetic tests since 2007 [6]. Tumor cells produce more exosomes than non-tumor ones. Exosomes have been proven involved in the formation of pre-metastatic niches, as well as in remodeling the tumor 
microenvironment [7]. Search for new biological media for non-invasive quantification of $P C A 3$ expression in patients will enhance cancer diagnosis and prognosis.

The goal hereof was to estimate PCA3 expression in urine sediments and exosomes to improve the prognosis of early recurrence in localized PC patients having undergone radical surgical treatment.

MATERIALS AND METHODS. The study was carried out by the Center for Urology, Nephrology, and Hemodialysis of the Anatomic Pathology Unit, Rostov Regional Hospital No. 2, in 2015-2017.

The study protocol followed guidelines for experimental investigation with human subjects in accordance with the Declaration of Helsinki and was approved by the ethics committee. Written informed consent was obtained from each patient (or an official representative) before the study.

The inclusion criteria were: (1) localized PC (T1c-T2c);

(2) radical prostatectomy (RPE) performed in patients; (3) no distant metastases. Surgical biopsy samples taken from 148 patients with localized PC (T1c-T2cN0M0) were tested histologically. Patients of the general clinical group were aged 54 to $79,65.6 \pm 2.5$ on average. The breakdown by stage was as follows: $\mathrm{cT}_{1 \mathrm{c}}$ in $9 / 148(6.1 \%), \mathrm{cT}_{2 \mathrm{a}}$ in $20 / 148(13.5 \%), \mathrm{cT}_{2 \mathrm{~b}}$ in $43 / 148$ (29\%), cT2c in 76/148 (51.4\%). The Gleason score was $\leq 6$ in 9/148 (6.1\%), 7 in 137/148 (92.6\%) and 8 to 10 in $2 / 148(1.3 \%)$ patients.

Histologically, PC was adenocarcinoma in all patients.

Upon entry and then every 3 months after RPE, patients' blood serum was tested for PSA by immunoassay using a Multiscan-P 2 photometer (Thermo Fisher Scientific Inc., Finland). Biochemical recurrence (BR) was diagnosed if PSA exceeded $0.2 \mathrm{ng} / \mathrm{ml}$ of blood in three consecutive samples spaced by a fortnight or more.

For genetic testing, the first step of preparing the samples was to collect $70 \mathrm{ml}$ of urine after prostate massage (pressing each lobe thrice). Once collected, $20 \mathrm{ml}$ of urine was centrifuged over 15 minutes at 3,000 rpm; the supernatant was further removed, and the sediment was resuspended and sampled in an Eppendorf tube, $1.5 \mathrm{ml}$ a sample. The remaining urine was preserved by adding $1 \mathrm{ml}$ of the RNA Medium (InterLabService LLC, Russia). To extract exosomes, $50 \mathrm{ml}$ of the postmassage sample was centrifuged over 15 minutes at 10,000 rpm; the resulting supernatant was centrifuged over 3 hours at 100,000 rpm. The sediment was washed by adding $3 \mathrm{ml}$ of phosphatebuffered saline (PBS), and then settled by short centrifuging. Exosomes were further resuspended in $200 \mu 1$ of PBS.

Total RNA was released by the sorbent method using an AmpliPrime RIBO-sorb set (NextBio, Russia) in full compliance with the manufacturer's guidelines. The samples were treated with DNase (6 Kunitz units) over 40 minutes at room temperature in an appropriate buffer (reagents from Applied Biosystems, USA) to remove genomic DNA.

Reverse transcription was performed using a High Capacity cDNA Reverse Transcription Kit (Applied Biosystems, USA). To produce cDNA on the RNA matrix, random oligonucleotides 
were annealed, which spent $40 \mu \mathrm{l}$ of the kit; the procedure was performed as instructed by the manufacturer's manual. PCA3 expression in urine sediment and exosomes was quantified by realtime polymerase chain reaction (real-time PCR). The research team compared the threshold cycles $C t$ for the studied gene and for a reference one. The reference was the human kallikrein gene KLK3, which features prostate-specific expression. The reaction mixture contained $1.0 \mu 1$ of the cDNA sampled from the urine sediment or exosome, $8.0 \mu 1$ of deionized water, $1.0 \mu 1$ of the reaction-ready mixture of primers and TaqMan probe, $10.0 \mu \mathrm{l}$ of a concentrated buffer solution with polymerase per the manufacturer's manual. The temperature parameters were as follows: denaturation at $95{ }^{\circ} \mathrm{C}$ over 10 minutes, then 4715 -second cycles at $95{ }^{\circ} \mathrm{C}$, then 1 minute at $60{ }^{\circ} \mathrm{C}$ for detection.

Real-time PCR used ready-made KLK3 primers (assay ID Hs02576345_m1, Applied Biosystems, FAM), PCA3 (assay ID Hs01371939_g1, Applied Biosystems, FAM), as well as TaqMan probes with dyes and minor groove binders, MGB. Urine samples were tested if KLK3 expression was detected at $C t$ of up to 45 cycles. The gene was amplified thrice in each sample to calculate the averaged $C t$.

Real-time PCR used a Bio-Rad CFX96 thermocycler (Bio-Rad, USA) and specialized software (Bio-Rad CFX Manager ver. 2.1). $\triangle C t=C t(P C A 3)-C t(K L K 3)$ was calculated as the value of $P C A 3$ expression.

For statistical processing, the researchers used Statistica 12 (StatSoft, USA): descriptive statistics and frequency analysis module, as well as crosstabulation tables. They calculated the median, the 25 th percentile, and the 75 th percentile. The intergroup difference in quantitative readings was estimated by the Mann-Whitney test at $\mathrm{p} \leq 0.05$. Differences in lobes were assessed by $\chi^{2}$. The researchers used ROC analysis.

RESULTS. PC may recur within months or years after conservative or radical treatment (which comprises surgery). Recurrence can be local, systemic, or biochemical, which only manifests itself as an increased serum PSA level. Thirty (20.3\%) of 148 examined patients were found to have biochemical recurrence within two years after RPE. Literature suggests that five-year post-RPE BR rates range from $15 \%$ to $30 \%$ in PC patients [4]. Thus, this study showcased trends consistent with earlier epidemiological data. The preoperative results of genetic tests were analyzed in retrospect in the context of two-year recurrence history and BR development, see Table 1.

Table 1.

Treatment group and control patients: Prostate-specific antigen concentration in serum and PCA3 expression in urine sediment and exosomes as a function of recurrence

\begin{tabular}{|l|c|c|c|c|}
\hline Indicator & $\begin{array}{c}\text { Sample-wide } \\
(n=148)\end{array}$ & $\begin{array}{c}\text { BR: yes } \\
(n=30)\end{array}$ & $\begin{array}{c}\text { BR: no } \\
(n=118)\end{array}$ & $p^{*}$ \\
\hline serum PSA, & 12.8 & 14.2 & 12.0 & 0.19 \\
ng/ml. Me $[25 \% ; 75 \%]$ & {$[9.2 ; 17.1]$} & {$[9.9 ; 18.8]$} & {$[8.8 ; 16.7]$} & \\
\hline
\end{tabular}




\begin{tabular}{|l|c|c|c|c|}
\hline $\begin{array}{l}\triangle C t \text { PCA3-KLK3 in } \\
\text { urine sediment. }\end{array}$ & $\begin{array}{c}-0.35 \\
\text { Me }[25 \% ; 75 \%]\end{array}$ & $\begin{array}{c}-0.44 \\
{[-0.54 ; 0.75]}\end{array}$ & $\begin{array}{c}0.06 \\
{[-0.55 ; 0.90]}\end{array}$ & 0.75 \\
\hline $\begin{array}{l}\Delta C \text { PCA3-KLK3 in } \\
\text { urine exosomes. }\end{array}$ & -2.01 & -2.37 & -0.95 & $\mathbf{0 . 0 4}$ \\
$\operatorname{Me}[25 \% ; 75 \%]$ & {$[-2.42 ; 0.87]$} & {$[-3.49 ; 0.55]$} & {$[-1.93 ; 0.98]$} & \\
\hline
\end{tabular}

Note: $\mathrm{p}^{*}$ stands for confidence probability of intergroup difference (with vs without BR).

Regardless of the BR course, PC patients did not differ significantly in the median and interquartile range of pre-surgery PSA, $p=0.19$, see Table 1.

The median and interquartile range of $\triangle C t$ for $P C A 3$ were similar in the two subgroups (as split by the course of the disease) to those of the reference gene $K L K 3$ in urine sediment, and did not differ significantly $(\mathrm{p}=0.75)$, see Table 1 . The studied gene had a negative mean $\Delta C t$ with respect to the reference gene, a sign of higher expression of the former.

Meanwhile, urine exosomes of the recurrent patients had higher PCA3 mRNA compared to their non-recurrent counterparts $(p=0.04)$. Median $\triangle C t P C A 3-K L K 3$ in urine exosomes was -2.37 initially in the BR patients, -0.95 for the rest, see Table 1 . A lower $\Delta C t$ indicated a higher level of the mRNA of the analyzed PCA3 as compared to the reference $K L K 3$ in urine exosomes. A higher $P C A 3$ expression in urine exosomes was associated with the subsequent BR. The research team ran frequency analysis and crosstabulation to study the association of these processes in detail, see Table 2.

Table 2

Number of PC patients with different PCA3 expression levels in urine sediment and exosomes with a breakdown by BR

\begin{tabular}{|l|c|c|c|c|}
\hline $\begin{array}{l}\text { Indicator and its } \\
\text { range }\end{array}$ & $\begin{array}{c}\text { Sample-wide } \\
(n=148)\end{array}$ & $\begin{array}{c}\text { BR: yes } \\
(n=30)\end{array}$ & $\begin{array}{c}\text { BR: no } \\
(n=118)\end{array}$ & $p^{*}$ \\
\hline $\begin{array}{l}\Delta C t \text { PCA3-KLK3 in urine } \\
\text { sediment: }\end{array}$ & $5(3 \%)$ & 0 & $5(4 \%)$ & \\
$>3.3$ & $65(44 \%)$ & $5(17 \%)$ & $60(51 \%)$ & $\mathbf{0 . 0 0 8}$ \\
{$[1.86-3.3]$} & $78(53 \%)$ & $25(83 \%)$ & $53(45 \%)$ & \\
$<1.86$ & & & & \\
\hline$\triangle C t$ PCA3-KLK3 & $6(4 \%)$ & $1(3 \%)$ & $5(4 \%)$ & 0.77 \\
in urine exosomes: & $142(96 \%)$ & $29(97 \%)$ & $113(96 \%)$ & \\
$>1.48$ & & & & \\
$\leq 1.48$ & & & & \\
\hline
\end{tabular}

Note: $p^{*}$ is the confidence probability for $\Delta^{2}$ in multiple comparisons. 
state is the differential point that separates PC and benign hyperplasia) was more frequent (83\% vs. 45\%, $p=0.008$ ). Therefore, comparing PCA3 expression in urine sediment is informative when it comes to evaluating the tumor recurrence risk.

Since Apolikhin et al. [8] proposed urine exosome $\triangle C t P C A 3-K L K 3=1.48$ as the threshold for concluding PC development risk when differentiating it from benign processes, the authors used ROC analysis to further find such $C t$ threshold that would effectively isolate patients at a high risk of recurrence. ROC analysis identified the separation threshold of $\triangle C t P C A 3-K L K 3 \leq-2.9$. That is, if a prostate adenocarcinoma patient had $\triangle C t P C A 3-K L K 3$ of -2.9 or below in urine exosomes, a high risk of BR with 24 months of RPE could be expected at a diagnostic sensitivity of $90 \%$ and a diagnostic specificity of $86 \%$. There were $10 \%$ false negatives and $14 \%$ false positives. The overall diagnostic effectiveness of quantifying urine exosome PCA3 expression to predict early post-PRE BR was $87 \%$. The area under ROC was $0.896 \pm 0.0007(\mathrm{p}<0.0001)$, suggesting that the method was highly informative.

For urine sediment, the $C t$ threshold that separated patients at a high risk of recurrence was 0.51 . That is, if a prostate adenocarcinoma patient had $\triangle C t P C A 3-K L K 3$ of -0.51 or below in urine sediments, a high risk of BR with 24 months of RPE could be expected at a diagnostic sensitivity of $87 \%$ and a diagnostic specificity of $85 \%$. There were $13 \%$ false negatives and $15 \%$ false positives. The overall diagnostic effectiveness of quantifying urine sediment $P C A 3$ expression to predict early post-PRE BR was $85 \%$. The area under ROC was $0.802 \pm 0.0004(\mathrm{p}<0.0001)$, suggesting that the method was highly informative.

Detecting PC recurrence by monitoring the serum PSA levels in lab tests is a common clinical practice. However, serum-only PSA tests result in overdiagnosing PC progression in $1.7 \%$ to $67 \%$ of all cases [4]. Despite the developed tactics and additional strategies for monitoring postoperative PSA levels in the serum of PC patients, which include adjustments for age, PSA level growth and doubling rates, marker isoforms, and PSA "density" [2], a wide range of biochemical and molecular genetic markers in various biological fluids and tissues must be tested for more accurate prediction of postoperative disease course.

The results of this research into PCA3 expression are in line with the data of other authors that analyzed the expression of $P C A 3$ and that of other genes of prostate-specific expression in whole urine, urine sediment, and urine exosomes $[5 ; 8]$. The authors underlined the informativeness of testing these biological fluids for differential diagnosis of benign and malignant prostate tumors. Apolikhin et al. [6] proposed estimating PCA3 expression in urine sediment and exosomes as a promising test for PC diagnosis. Applying this method improved early PC detection while avoiding unnecessary biopsies. Continuing the development of a non-invasive PC patient monitoring system, the authors hereof estimated PCA3 expression in urine sediment and exosomes sampled from BR and non-recurrent PC patients before surgery. This approach helped assess the prognostic value of estimating $P C A 3$ expression in urine sediment and exosomes to evaluate the early recurrence risks 
before surgery. The research effort identified urine sediment and exosome PCA3 expression levels, exceeding which could indicate a risk of early disease progression. Thus, the key finding is that estimating PCA3 expression in urine sediment and exosomes is informative for predicting BR within two years of RPE, albeit with some constraints.

\section{CONCLUSIONS.}

1. $\quad P C A 3$ expression in post-massage urine sediment and exosomes sampled from localized-PC patients has a higher prognostic value for predicting post-RPE BR risks than serum PSA.

2. A higher PCA3 expression is associated with a higher risk of BR within two years of RPE. Evaluating the risk of localized PC progression by PCA3 expression as found by real-time polymerase chain reaction has a diagnostic effectiveness of $85 \%$ for urine sediment, $87 \%$ for urine exosomes.

\section{FINANCIAL SUPPORT AND SPONSORSHIP \\ Nil.}

\section{CONFLICTS OF INTEREST}

The authors declare no conflict of interest

SUPPLEMENTARY DATA (DOI)

\section{REFERENCES}

1. Ed by Kaprin A.D., Starinskii V.V., Petrova G.V. State of oncological care for the population of Russia in 2016 [Sostoianie onkologicheskoi pomoshchi naseleniiu Rossii v 2016 godu]. Moscow, MNIOI im. P.A. Gertsena, 2017, 236 p.

2. Sergeeva N.S., Skachkova T.E., Marshutina N.V. Clinical significance of PSA-associated tests in the diagnosis and staging of prostate cancer. [Klinicheskaia znachimost' PSA-assotsiirovannykh testov v diagnostike i stadirovanii raka predstatel'noi zhelezy]. P.A. Herzen Journal of Oncology Onkologiya. Zhurnal imeni P.A. Gertsena, 2018, no 1, pp. 55-67, doi 10.17116/onkolog2018715567.

3. Sidorenkov A.V., Govorov A.V., Pushkar D.Yu. et al. Russian PCA3 test-system: first results [Rossiiskaia test-sistema RSA3: pervye rezul'taty]. Experimental and Clinical Urology - Eksperimental'naia $i$ klinicheskaia urologiia, 2014, no 2, pp. 36-43.

4. Louie K.S., Seigneurin A., Cathcart P. et al. Do prostate cancer risk models improve the predictive accuracy of PSA screening? A meta-analysis. Annals of Oncology, 2015, vol. 26, no. 5, pp. 848864, doi 10.1093/annonc/mdu525.

5. Mikhaylenko D.S., Novikov A.A., Grigor'eva M.V. Comparative analysis of the PCA3 gene expression in sediments and exosomes isolated from urine [Sravnenie ekspressii gena RSA3 v 
osadkakh i ekzosomakh mochi pri rake predstatel'noi zhelezy]. Cancer Urology - Onkourologia, 2017, vol. 13, no 3, pp. 54-60, doi 10.17650/1726-9776-2017-13-3-54-60.

6. Valadi H., Ekstrom K., Bossios A. et al. Exosome-mediated transfer of mRNAs and microRNAs is a novel mechanism of genetic exchange between cells. Nature Cell Biology, 2007, vol. 9, no. 6, pp. 10.1038/ncb1596.

7. Krasil'nikov M.A., Zborovskaia I.B. Molecular carcinogenesis [Molekuliarnyi kantserogenez], Moscow, OOO ID «ABV-press», 2016, 418 p.

8. Apolikhin O.I., Sivkov A.V., Efremov G.D. The first Russian experience of using PCA3 and TMPRSS2-ERG for prostate cancer diagnosis [RSA3 i TMPRSS2:ERG $\mathrm{v}$ diagnostike raka predstatel'noi zhelezy: pervyi opyt primeneniia kombinatsii markerov v Rossii]. Experimental and Clinical Urology - Eksperimental'naia i klinicheskaia urologiia, 2015, no 2, pp. 30-35. 